\title{
REVIEW ARTICLE \\ A BRIEF ANALYSIS OF THE APPLICATION OF FLOMM HUMANISM TO CONTEMPORARY SOCIAL PROBLEMS
}

\author{
Liu Chuanlei* \\ Heilongjiang Bayi Agricultural University \\ *Corresponding Author Email: mmpphehe@126.com
}

This is an open access article distributed under the Creative Commons Attribution License, which permits unrestricted use, distribution, and reproduction in any medium, provided the original work is properly cited

\section{ARTICLE DETAILS}

\section{Article History:}

Received 1 January 2019

Accepted 20 February 2019

Available online 22 February 2019

\begin{abstract}
In Fromm's thought, the most important one is humanism. The socialization problem in modern human society is not only the problem of social system, but also the problem of human personality and psychology. Therefore, in order to reduce the occurrence of social destructive phenomena, it is necessary to reduce human destructive behavior. Through psychological analysis and theoretical study, we can improve people's psychological potential and optimize their sociality, so as to create and maintain good social forms.
\end{abstract}

\section{KEYWORDS}

Fromm, Humanistic thought, Social problems

\section{INTRODUCTION}

Flomm, an American German Jewish philosopher and psychoanalytic psychologist, is regarded as one of the founders of psychoanalytic sociology [1]. Because he inherited and developed the Freudian psychoanalysis, and at the same time harmonized the Freudian psychoanalysis and Maslow's humanistic theory to study the western spiritual situation after the two world wars [2]. Flhelom's psychoanalysis has its own views on personality theory, dream analysis, psychotherapy and ethics. He not only USES the knowledge of philosophy, but also plays the role of psychoanalysis, integrates the ideological achievements of contemporary western philosophy, sociology, anthropology, history and religion, and explores the mystery of human nature and soul [3].

Fromm used to follow Freud, but later his relationship with Freud changed due to his different ideas in the part of humanistic philosophy, so he also opened up a new theoretical direction in psychology [4]. He tried to study the influence of society on people fromm a macroscopic perspective, introduced psychoanalysis into the field of social history, proposed the concept of social subconscious, social character and so on, and formed his social psychoanalysis theory [5]. This not only enriched and developed Freud's classical psychoanalysis theory, but also probed into the improvement of modern people's situation and mental state [6]. This paper mainly analyzes fromm's humanistic theory: the social perfection of human beings and the solution of social problems.

\section{MASTER THE ART OF LOVE, HAVE MATURE LOVER'S ABILITY}

\subsection{Define the Importance of Self-Love and Forge A Lover's Ability}

Fromm believes that love is an art that requires knowledge and effort. But most people think that love is just an occasional feeling that only the lucky ones can "fall into" it for three reasons. The second is to think that the problem of love is an object problem, not an ability problem. Third, people do not understand the difference between falling in love and enduring love [7].
In contemporary society, lovelorn seems to be the normal state of young people's emotional life. People say to themselves that they are looking for true love, but they don't actually know how to love. Zhang ailing said like a person, would humble to dust, and then out of a flower. However, this kind of liking is precisely because they do not know how to love themselves [8]. If they think that love is humble, they can get the response of others, but eventually they are just picked and thrown in the wind and dust. But in fact, many people are like a flower, a brilliant waiting for the capture of the loved one, and its flowers are also in the moment of being taken to disappear. Therefore, the lover should be on the basis of self-love, with a rich and abundant heart, in order to love their loved ones in an equal and appropriate manner [9].

In fromm's the art of love, self-love is not "selfish ", but the basis of love for others. The affirmation of one's life, happiness, growth and freedom are based on the ability to love, that is to say, whether you have the ability to care, respect, be responsible and understand people. If one has the ability to love creatively, one must love oneself, but if one loves only others, one has no ability to love. Only when we clearly understand the meaning of self-love, can we understand what kind of thoughts and expectations a person will have for the emotion of love, the behavior of love and the demand of love [10]. Only in this way can we truly start fromm loving the other party to give ourselves love, instead of actually satisfying our own needs for emotion. Like fromm, love is a positive concern for the person you love, and if there is no such positive concern, it is not love.

\subsection{Serious marital behavior can reduce the rate of marriage failure}

In recent years, marriage and family dispute cases in China have been running at a high level. Fromm 2013 to the end of October 2015, nearly 4 million cases of marriage and family dispute cases were concluded in courts across the country. Divorce cases also remain high. In December, du wanhua, a full-time member of the judicial committee of the supreme people's court, told the media that there were about 1.6 million cases of marriage and family in 2014, including more than 1.2 million cases of divorce [11]. 
According to the data, in the first half of 2016, a total of 1.683 million couples handled divorce procedures in accordance with the law, an increase of 11 percent over the previous year. A total of 3.841 million couples went through divorce procedures in accordance with the law in 2015 , an increase of 5.6 percent over the previous year. The crude divorce rate was 2.8 per thousand, an increase of 0.1 point over the previous year. China's divorce rate has been rising since 2002. In 2002, China's crude divorce rate was only $0.90 \%$, in 2003 , it reached $1.05 \%$, and in 2010 , it exceeded $2 \%$. Current data show that the crude divorce rate was 2.8 per thousand in 2015, more than three times as high as in 2002 [12].

Six of the main reasons for divorce were: cheating, domestic violence, personality clashes, bad relationships between mother-in-law and daughter-in-law, bad habits and property purchases. According to the survey, 50.16 percent of divorces in China are caused by a third person, whose infidelity is the top reason for thinking about divorce.

When one spouse's "dignity" is repeatedly violated, and repeatedly advised not to change; It means that the foundation of a couple is crumbling. Family life is also a part of social life. Social life, the relationship between superiors and subordinates, and the relationship between colleagues should respect each other. Fromm believes that there are four essential elements of love: care, responsibility, respect and understanding [13]. To think that the experience of love only represents one's failure to truly understand the nature of love. He USES the story of Rio to illustrate how care and responsibility are rare in today's relationships. Fromm said that people in modern society lack respect for the freedom of others and know little about the real hopes and needs of others.

In fromm's art of love, the essential element of true love is "give" rather than "get". "give" is the highest expression of power, and it is through "give" that I can experience my power, my "wealth" and my "vitality". In the marriage life, the husband and wife should know how to respect and give, instead of simple demand, or the inclination to meet their own needs, but ignore the other side's needs and feelings. Any one of the one-way pursuit behaviors may bring harm to the other party, so in the marriage life, both the husband and wife should take their behaviors in the marriage life seriously and avoid the marriage injury.

\subsection{Face "tiger mother, cat father, Wolf father" and regulate family education}

There were tigers and wolves, separated by cats and sheep. This is not a children's song, but a true reflection of the current situation of Chinese family education.

"Tiger mother" Amy chua sparked a bitter dispute between China and the United States over parenting by publishing "battle hymn of the tiger mother." She insisted on "Chinese education", sternly disciplining her two daughters and demanding that they not stay out overnight. No party parties; Do not watch TV or play computer games frequently. You can't choose your favorite extracurricular activities. No academic achievement in any subject shall be lower than A; No piano or violin at the age of 14 , the eldest daughter played the piano at Carnegie music hall under the strict instruction of the tiger mother, while the youngest daughter became the chief violinist of the Yale youth orchestra at the age of 12 .

Xiao baiyou, a "Wolf father", insisted that "children go to Peking University every day after being scolded". He insisted on "education his own children in the most traditional and primitive way". "Wolf dad" is not allowed to watch TV, not free access to the Internet, not open air conditioning; 'the children are the people, the parents are the Lord,' he said. Fighting is a culture. He "scored three kids into Peking University".

These "tiger moms" and "Wolf dads" have succeeded to some extent, but they have also deprived themselves of the emotional needs of childhood. "Cat dad" chang thinks education can also be gentle, with easy steps and a waltz with children, just like a cat, and parents should not make choices for their children. He advocates individualized education for children. Parents should be tolerant and good at communicating with their children. Education children should be given more freedom on the premise of abiding by the "rules of the game". He said parents should give their children more freedom and more things to make their own decisions. His daughter ended up at Harvard
Fromm thinks of the love between a parent and a child: motherly love is a blessing, a peace, that doesn't have to win it, and doesn't have to work for it. But unconditional maternal love has its drawbacks. This kind of love not only does not need to exchange with the effort, but also simply cannot win. If there is maternal love, there are blessings; Without maternal love, life would be empty, and we have no power to arouse it. The essence of fatherly love is that obedience is the greatest morality, disobedience is the greatest $\sin$, and disobedience will be punished by the loss of fatherly love. The positive side of fatherhood is also important. Because fatherly love is conditional, we can earn it through our own efforts. Unlike motherly love, fatherly love is subject to our control and effort. A mature man will eventually reach the heights of being both his mother and his father. He developed a mother's conscience and a father's conscience.

However, in Chinese family education, these parts are neglected, but more of the future of the cultivation and hope, fromm childhood to their knowledge and ability training. However, many new parents in China who are unfamiliar to family education and despise family education will also go the way of traditional education. Therefore, it is the most important thing to change the traditional family education concept and have a good education way and understand the role allocation and responsibility of paternity and maternal love in children education, so as to make gradual progress due to favorable trend.

\section{GIVE FREEDOM A YARDSTICK AND GIVE FULL PLAY TO ITS UTILITY}

3.1 Clear treatment of "negative freedom" and "positive freedom" helps college graduates to reduce confusion

Some experts use a word to describe the confusion of contemporary college students: "the spirit of the youth dissipated, mature into did not come." But the graduate faces the choice, has the confused mentality. It will be a big test of life for many college graduates to find the right way for them.

\section{Confused one: to make "sardines" or "dead salted fish"}

"North Shanghai, guangdong", more job opportunities, but life pressure, people like "sardine"; Back home, life pressure is small, but may be lost in the small city of mediocrity and solidification, like the big city abandoned "dead salted fish". Leave or stay, this is in front of a large number of graduates must choose the topic.

\section{Confused 2: to be "highly educated" or "experienced"}

On the one hand, I want to enter the society as soon as possible to solve the difficulties for my family, increase my work experience and enrich my life experience. On the other hand, I hope to improve my job competitiveness through further study, or to delay the time to face employment pressure. Going to school, or looking for a job, is another choice many colleges graduates face.

\section{Confused three: "wide net" or "alone love"}

In the process of job-hunting, some graduates choose "casting net widely, fishing for more fish", sending resumes by sea, taking written tests and interviews, and constantly experiencing elimination and being eliminated. Some graduates are "exclusively interested" in certain industries or positions. However, some people are physically and mentally exhausted fromm running around, while others lose themselves after long periods of persistence.

In escape from freedom, fromm mainly explores the relationship between human nature and freedom in the historical process. Fromm believes that human beings realize individualization in the complex social relationship system, and social and historical conditions and their environment determine human personality structure and characteristics. On the one hand, people get more and more freedom because of their increasing individuality. On the other hand, due to the increasingly cruel and hostile relations between people, people feel more lonely and uneasy psychologically. People try to escape the social freedom through various ways because they can't stand the loneliness and loneliness that comes with freedom and even suffer from mental illness. This is of certain guiding significance for the analysis of the deep psychological problems of young people's confused and ignorant behavior in contemporary society. 
Use of fromm's theory, we can understand, in the face of employment and the choice of one's deceased father grind, but it is not lost, but an anxious state of mind, because everyone has his own strong side, everyone has his own hard work, each of us has our own the positive side, but we didn't recognize their value, not sure what you can do, is also afraid to miss a better life. We don't know, we never want myself to fail, so we choose to stay in front of contradictions, stop and look at how to do ability to you will be successful, but the answer will not in practice without activity appeared, us or more likely to borrow, but life is our, so only know their own value, and match the oneself the desired, to get rid of the confusion, make the right choice.

\subsection{Mark the line of freedom, overcome character defects and get rid of procrastination}

Procrastination is the act of failing to regulate yourself and putting off what you plan to do when you can anticipate the consequences. Procrastination is a common phenomenon, with a survey showing that about 75 percent of college students believe they procrastinate at times and 50 percent believe they procrastinate at all times. Severe procrastination will bring negative effects on the physical and mental health of individuals, such as the occurrence of strong remorse, guilt, constant self-denial, belittling, accompanied by anxiety, depression and other psychological diseases. Once such a state occurs, attention should be paid to it.

Fromm thinks that the scale of capitalist society's pathological and unjust is that it does not conform to human nature and human needs. Therefore, he proposed that human beings have five kinds of needs: the corresponding needs. An individual has the need to love and be loved, wants to know, understand and care for others, and is willing to take responsibility for others. Exceed your needs. It refers to the individual's desire to surpass the limitation of material conditions and to show creative personality traits in spirit. Implement requirements. An individual's desire to be close to others, society and nature, and thus to achieve a sense of well-being; Aggregate demand. It refers to the psychological tendency of individuals to strive for personal integrity and hope to live a meaningful life in the world. Directed requirements. It refers to the psychological tendency of an individual to strive for direction in life so as to gain peace of mind.

When human nature and human needs do not match, a series of negative work feeling will appear, thus deepening the procrastination. To borrow from fromm's expectation theory: the intensity of an activity's motivation for arousing the initiative of a certain person and inspiring the internal potential of a person depends on the value of meeting the individual's needs after reaching the goal -- the valence and the probability that he will make judgment based on previous experience to lead to the result -- the expectation. By addressing the human impact of procrastination, we can reinforce our own alignment and needs.

So we judge the value of a good self, and actively seek what you want to reach the level of, do a good job in primary and secondary order, and to work effectively, and in each small task is completed, all of our execution a reward, to eliminate the interference at the same time, gradually strengthen their inner demand, heart and soul to do things.

\subsection{Harmonize "jurisprudence" and "reasonableness" to reduce hidden harm in judicial treatment}

Since "freedom" is not in itself an experience we enjoy, fromm argues that many people do not use it successfully, but rather seek to minimize its negative effects by developing certain ideas and practices that provide some form of security.

Fromm pointed out that when a country is experiencing negative freedoms, it is likely to succumb to authoritarian regimes, but he also made clear that the results of cultural evolution so far cannot be obliterated, and that nazism did not create real unity for the world. This is similar to the application of emotion and law in case handling. In the one-way application of law, the relevant personnel of the case may obey the judgment of the law, but implicitly they will be negative to the relevant law, so as to make extreme behavior. In contemporary judicial cases, rigid laws and regulations tend to be satisfied with social punishment, but in fact, the standard of social justice lies in people's recognition of it. When the handling of the case is only ignorant in applying legal principles and ignoring the common sense, that is, ignoring people's emotional needs, it will also cause the dissatisfaction of the personnel involved in the case, so it may cause hidden harm. Therefore, in the case handling, we should not only apply legal principles, but also pay attention to reasonable. The combination of the two can not only serve the public, but also reduce the hidden damage.

Since the case of "old people fall down", the issue of "social integrity" has caused great waves, and now, judicial trust has also become a major social issue. A political situation that does not care about the feelings of the nation is like a senseless official, and the so-called justice is just cold blade. Fromm argues that capitalism is the source of high crime. Because the country excessively pursues the capital economy, but neglects the humanity sentiment, the social balance is broken, the social question can only be intensified, does not have the money, the people can live the hardship; But without feelings, people can't live. We are a socialist country. This so-called "justice" is not only about the economy, politics and culture of the "society", but also about our national feelings, because the citizens are the foundation of the national society.

\section{GUIDE THE BENIGN DEVELOPMENT OF RELIGION AND PSYCHOLOGY AND ESTABLISH CORRECT VALUES}

\subsection{Use religious thoughts to relieve mental stress and reduce the incidence of mental illness}

According to the latest epidemiological statistics of the ministry of health and clinical data of mental hospitals at all levels, there are about 16 million patients with major mental disorders such as depression and schizophrenia in China, with the incidence of about $1-1.5 \%$. About $70 \%$ of the patients with mental diseases can live and work normally through reasonable drug and psychological treatment, and about 30\% May develop into severe mental diseases. Such patients need long-term systematic treatment and effective care and supervision.

Fromm believes that all guilt and shame stems from a sense of dissociation. The only way to resolve this division of existence is to fully develop humanity's unique characteristics - love and reason. Reason can be explained by zen and psychological analysis, which teaches people meditation and the development of psychological potential. Use the relationship between psychology and zen, give play to the effect of zen, so as to maintain psychological stability.

Due to the increasing pressure of life, the incidence of mental illness has increased in contemporary society. In order to solve this problem, it is necessary to understand people's deep psychological problems, so as to relieve depression and seek positive evolution of spirit. When people are difficult to face reality, they often choose to escape, and fromm's ontology clearly expresses such a view that "the meaning of life lies in the process of living". Using this perspective, we should understand that in real life, people should reject idealism, give play to the role of human beings to society in a realistic way, and at the same time, enrich their inner mind through zen Buddhism, and have higher self-confidence and willpower to face the pressure in life.

\subsection{Find out the deep psychological factors of destructive behavior of} human, timely adjust and reduce crime rate

Crime is a universal social phenomenon in all kinds of social forms since mankind entered class society. However, there are different causes of crime in different social forms.

Bourgeois scholars have done a lot of research on the causes of crime in capitalist society. For example, based on the principles of natural science, the criminal human school studies the relationship between the criminal's appearance, bones, physique, psychology and other personal characteristics and the crime, and maintains that the crime is determined by the criminal's physical and psychological characteristics. C. lombroso, an Italian criminal anthropologist, once put forward the concept of "born criminal", believing that the reason for the crime is mainly due to the fact that some people are born with the characteristics of crime. According to the physical and psychological characteristics, he divided the prisoners into hereditary offenders, habitual offenders, maniacs offenders, passion offenders, accidental offenders and so on. For example, the school of 
criminal sociology focuses on the relationship between crime and social environment.

And frome people deal with loneliness in the capitalist society discussed several psychological mechanism of what he called the character of the dynamic tendency, which accepted tendency, the tendency of people do not have to produce or provide the ability of love, everything he needed to fully seek to help others, dependent on others, the recipient, rather than the giver. And exploitative, this kind of tendentious person, do not expect to accept, but depend on its violence, trick and so on, steal from other people, satisfy oneself desire. This also explains the occurrence of criminal behavior, for this, we should find out the trend early and respond accordingly.

For the first time in human history, marxism has revealed the social and economic conditions and class roots of crime, and pointed out that private ownership is the root cause of crime in all countries ruled by exploiters, and the capitalist system itself is the root cause of crime in capitalist society. Due to the contradictions of the capitalist system itself, the crime rate in the capitalist society is increasing year by year. However, in order to effectively control the occurrence of criminal ACTS, we can analyze the multi-layered causes of human behavior by studying flomm's destructive analysis of human beings, and analyze the good and evil nature of human beings. For people with psychological diseases, it is suggested that treatment and rescue should be carried out according to the psychological needs of patients and the disposition tendency of their personalities. According to fromm's theory of personality tendency, only the creative tendency is the normal and healthy expression of personality.

\section{CONCLUSION}

Flomm devoted all his life to studying the problem of "human", focusing on human, human nature, human alienation and human liberation. His theory of human nature integrates Freud's psychoanalysis theory and Marx's theory of human beings, and also absorbs the essence of outstanding cultural thoughts such as judeo-christianity and buddhist zen, which is the core and cornerstone of his whole social philosophy theory. Through the research and application of flomm's ideological theory, we can put forward the method and plan of managing the symptoms and the root causes of contemporary social problems, so as to solve social problems, optimize social environment as the guidance, and form a civilized and harmonious, sentient and loving social family.

\section{Acknowledgements}

Project research funding project of the national communist youth league of China (project approval no. 2018ZD46) One of the achievements of the project (project number: GBD1317068) of education science 13th five- year plan of Heilongjiang province.

\section{REFERENCES}

[1] Fromm, E. 2008. Art of love. Translated by Zhao Zhengguo. Beijing: international culture publishing company.

[2] Tan, R. 2003. Human resource management in the public sector. Edition 1 . Tianjin: Tianjin university press.

[3] Suzuki, T., Fromm. 2012. Zen and psychological analysis [M]. Translated by Martino. Hainan press.

[4] Guo, Y.Y. 2001. Isolated modern man -- the humanistic psychoanalysis of Flomm. Wuhan: Hubei education press.

[5] Fromm, E. 2006. Psychoanalysis and religion translated by Sun Xiangchen. Shanghai people's publishing house, 8-1.

[6] Shan, W. 2010. Analysis of Flomm's alienation thought [M]. New exploration of political and ideological theory education. Published by Zhejiang Gongshang university press.

[7] Liu, J. 2011. Analysis of human destructiveness and its root cause [D]. Harbin: Harbin normal university.

[8] Zhao, J., Wang L.P. Discussion of Flomm's theory of human needs [D]. Longnan Normal College, Chengxian county, Gansu province.

[9] Yang, L. 2007. What is love - A review of Fromm's art of love [J]. Journal of Chongqing technology and business university (natural science edition), 21(5), 83-87.

[10] Shen, P.X. 2016. A brief analysis of the psychological mechanism of Fromm's escape from freedom -- based on the perspective of Marxist freedom view [J]. Journal of Huaihai Institute of Technology (Humanities and Social Sciences Edition).

[11] Sun, C. 2012. Analysis of Flomm's escape from freedom [J]. Daguan Weekly, 44.

[12] Ding, M. 1999. Comment on Fromm's escape from the psychological mechanism of freedom [J]. Learning and exploration, (1), 54-56.

[13] Yin, X.R. 1994. The dilemma of human nature, morality and modern people - comment and analysis on Fromm's humanistic ethics [J]. Academic journal, (8), 22-28. 